\title{
Chronobiological Risks in Occupational Health and Safety
}

\author{
Sorokin Gennadiy* \\ Northwest Public Health Research Center, Saint-Petersburg, Russia \\ *Corresponding author: Sorokin Gennadiy, Northwest Public Health Research Center, Saint-Petersburg, Russia
}

\section{ARTICLE INFO}

Received: 幽 December 23, 2020

Published: 幽 January 04, 2021

\section{ABSTRACT}

Citation: Sorokin Gennadiy. Chronobiological Risks in Occupational Health and Safety. Biomed J Sci \& Tech Res 32(5)-2021. BJSTR. MS.ID.005322.

\section{Introduction}

Chronobiology of performance and fatigue is the scientific basis for studying the impact of occupational stressors on the health of employees, including in the development of Fatigue Risk Management Systems, including the development of biomathematical models of fatigue. When the combination of frequency, amplitude and duration of acute fatigue does not allow the human body to recover, there is a chronobiological risk of chronic fatigue (chronic fatigue syndrome, CFS). The prognostic chronobiological model risk of CFS developed by us is based on the following General provisions:

a) Intensity (IW), duration of the working day (DWD) and week (DWW) are the main parameters of the workload, human performance is defined as a set of physiologically acceptable combinations of IW with DWD and DWW. To date, there are many methodological difficulties that arise when evaluating IW [1].

b) It is advisable to define professional CFS (overfatigue) as a pathological stage of chronic fatigue of an employee caused by a combination of frequency, amplitude and duration of acute fatigue, inadequate recovery capacity of mechanisms of voluntary regulation of activating systems of the brain. The duration of acute fatigue state for a working day and a week at various combinations IW with DWD and DWW is established [2].

c) A key attribute of professional CFS is the deficit of rest (DR). Depending on the time scale, you should study the daily (DRd), weekly (DRw), monthly (DRm) and annual (DRa) rest deficit. Using the "long hours of work" as an indicator of workload and the main cause of CFS, it is defective if the physiological IW is not taken into account at the same time.

d) The predicted output parameter of the model is a measure of the tendency of the population risk of developing CFS, an annual increase in the risk of CFS (AIRcfs). The actual value of AIRcfs is estimated at \% (annual increase in the frequency of CFS and and related chronic diseases, for example hypertension) and relative to the background values AIRcfsbg $=0.5 \%$ of that observed in the successfully ageing population (healthy ageing), with no harmful exogenous factors.

e) When analyzing complex cause-and-effect relationships of CFS development in full-scale conditions, it is necessary to use Express methods. The indicator used by us for rapid diagnosis of CFS and to study its causes summarizes the quality, frequency and severity of the seven most common psychosomatic symptoms observed in an employee during six months: 1-headache; 2 - dizziness; 3 - unpleasant sensations in the heart; 4 disorders of appetite and digestion; 5 - sleep disorders; 6 - irritability; 7 - anxiety [3].

f) The development of the model of CFS was carried out within the framework of a chronobiological approach to the analysis of sources of occupational risk and its consequences. The IW parameter is an integral estimate of the density and pace of the labor process. The daily and weekly DR is determined based on the difference between the hours of rest available to a person during non-working periods and the hours of fatigue 
after the end of the working day. Deflection values of AIR from the background value ("population standard pace of aging," AIRbg), is a criterion for assessment of the consequences of the risk intensity of the process of health disorders. In chronobiological aspect, there are two interrelated types of DR, which jointly affect the AIR, but have different physiological nature and prevention measures: lack of rest during wakefulness and sleep debt.

g) When determining DR in terms of the duration and intensity of the labor process, a quantitative assessment scale is used, which is uniform for dynamic works consisting of discrete actions, the intensity of which is measured by their pace, and for static, non- discrete actions with non-tempo work of the tracking type. The Central physiological mechanisms of functional tension of the human body are the same for tempo sensorimotor actions, without significant physical effort, and for non-tempo actions in the tasks of readiness, attention (vigilance). The chronobiological scale of assessment of tempo and non-tempo labor actions is based on the degree of fatiguering of the labor process. Based on the results of mass work studies, the following standards were established for assessing the intensity of labor for a working day and week [4]; determination AIR of chronic fatigue syndrome and related diseases with physiologically inadequate combinations of it with DWD and DWW [5], as well as when working in harmful conditions [6].

\section{References}

1. Boisard P (2003) Time and work: work intensity. European Foundation for the Improvement of Living and Working Condition. Dublin p. 8.

2. Sorokin G (2008) Chronophysiological Study of Occupational Fatigue. Human Physiology 34(6): 715-721.

3. Sorokin GA (2018) Integral assessment of psychosomatic symptoms of professional burnout and its prevention. Vestnic Roszdravnadzora 1: 40-45.

4. Sorokin GA (2001) Normalization of work intensity by its duration, density, and pace. Meditsina truda i promyshlennaya ekologiya 10: 2832.

5. Sorokin GA (2014) Definition and evaluation of rest deficit in different combinations of labor intensity with the duration of the working day and week. Proceedings of the International np. conferences. Labor psychology, engineering psychology and ergonomics St. Petersburg pp. 422-428.

6. Sorokin GA (2016) Work, fatigue and professional risk [Work, fatigue and occupational risk]. St. Petersburg: Polytechnic University pp. 456.

\section{ISSN: 2574-1241}

DOI: $10.26717 / B J S T R .2021 .32 .005322$

Sorokin Gennadiy. Biomed J Sci \& Tech Res

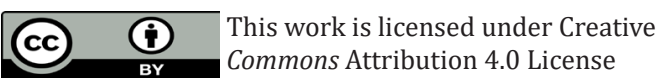

Submission Link: https://biomedres.us/submit-manuscript.php

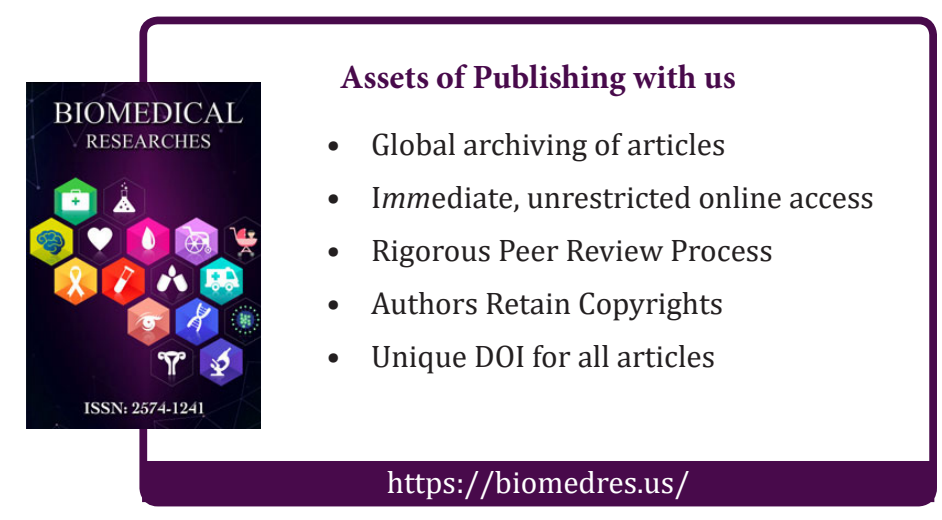

